\title{
Changes in the effects of fixation upon apparent distance in the third dimension'
}

ROBERT H. POLLACK

INSTITUTE FOR JUVENILE RESEARCH, CHICAGO

One hundred sixty children, kindergarten through seventh grade, were tested to determine the effects of fixation on the apparent distance from $S$ of objects in space. Children in grades 1-7, like adults, moved a comparison stimulus away from themselves to match a standard after a period of exposure to the standard above. Kindergarten children displaced toward themselves. Dis placement was correlated with chronological age, but not with mental age or interpupillary distance. According to the ontogenetic application of the sensory-tonic theory of perception, the younger children assimilate sensory stimulation from the extraocular muscles involved in convergence as part of their visual experience. Older children apparently compensate for these cues.

Wohlwill (1963) cited a series of studies which show a clear trend toward overconstancy of both size and distance as a function of increasing chronological age through childhood. The amount of this overconstancy varies inversely with the distance between a target and the eyes, and the overconstancy and gross measures of intelligence are not correlated. These findings suggest a mechanism involving physiological aging within the sensory apparatus unrelated to central intellectual operations (Pollack, 1963b, 1965).

In a study of a third-dimensional figural aftereffect in which the inspection target (IF) was used as its own test target (TF), Pollack (1963a) found that TF increased in apparent distance from adult $\mathrm{Ss}$ following a period of fixation. The sensory-tonic field theory of perception (Wapner \& Werner, 1957) was invoked to account for the displacement. It was suggested that during fixation, sensation due to the strain of convergence was built up. Since instructions to $S$ to fixate the target precluded direct muscular counteraction to this strain, counteraction took place instead in perception, producing an apparent displacement of the target away from $S$. Counteraction of this sort had already been found to be a typical adult response with other phenomena (Wapner \& Werner, 1957). Younger children, who tend to assimilate to muscular involvement rather than to counteract it, might, in this situation, assimilate the target to the strain of convergence and thus displace it toward themselves.

Overconstancy data for short distances show its onset at about age seven. It seems possible that underand over-constancy of distance, and therefore size, may be due to assimilative or counteractive displacements of targets related to convergence. If this were the case, flxated targets should be displaced toward Ss under age seven and away from older Ss.
Furthermore, increasing interpupillary distance, since it increases convergence, might lead to an increased counteraction effect beyond age seven. Alpern points out (1962b, p. 186), however, that although an adult must converge his eyes 2 prism diopters more than a young child, there is no evidence of an age effect on the accommodation-vergence ratio (Alperm, 1962a) such as there is on accommodation.

Subjects 2

One-hundred sixty school pupils served as Ss. Each of eight grade levels, kindergarten through seventh grade, was represented by 20 children (10 males and 10 females) all with $20 / 30$ or better uncorrected acuity and without marked exo- or esophoria. The mean ages for each grade were 66.9, 79.25, 92.25, $102.35,116.5,125.9,139.6$, and 152.0 months.

\section{Apparaius}

The targets were two square vertical rods $2^{\circ} 52^{\prime}$ high $x$ 30' wide, set 2029'20"' apart at a viewing distance of $40 \mathrm{~m}$. in a black tunnel. Each rod carried its own lllumination and could be moved on a track toward or away from S. Midway between the rods was a small fixed illuminated point (FP). Stimuli were viewed directly through a binocular eyepiece. Each rod could serve as IF-TF or as comparison object (CF), and inspection time of either could be precisely controlled by electronically-timed shutters. Eyepiece and $S$ were enclosed within a black shield and all were located in a completely darkened chamber. The rods were connected to two horizontal bars placed out of sight at hand level for a seated S. S adjusted the distance of the target from his eyes directly by moving the horizontal bars toward or away from himself. A direct pen recording system provided the measures of rod displacement.

\section{Procedure}

Initially both rods were set $1 \mathrm{~m}$ from the eyes. $\mathrm{S}$ was requested to set the right hand rod so that it appeared at the same distance as the left hand rod while he fixated the dot between them (pretest). Then, while $S$ closed his eyes, the right hand rod was screened by a black shutter. The $S$ was then instructed to fixate the dot with only the left hand rod present for 30 sec. Immediately following fixation the shutter was opened and $S$ was requested once more to set the right hand rod in the same fronto-parallel plane as the left one (posttest). The measured difference between pretest and posttest in seconds of visual angle displacement was taken as the aftereffect of fixation. 


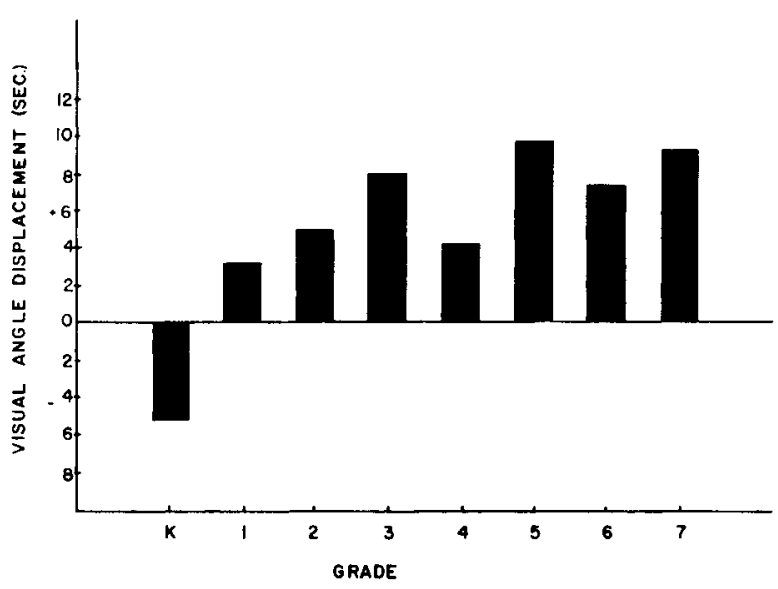

Fig. 1. TF displacement as a function of school grade (positive values indicate displacement of TF away from $S$; negative values indicate displacement toward $S$ ).

In addition, measures of the interocular distance of all Ss were taken with a Shuron Pupillometer and IQ scores were obtained from school records.

\section{Results and Discussion}

An overall $t$ test showed a significant difference between pretest and posttest settings $(t=3.66, d f=$ $159, \mathrm{p}<.001)$. Displacements were significantly correlated with chronological age (CA; r =.22, df $=158$, $p<.01$ ), but not with mental age (MA; $r=.10)$. Since the correlation with $\mathrm{CA}$ was low, and since only the kindergarten group appeared to differ qualitatively from the others, a $t$ test was carried out comparing the kindergartners with all others. The difference between the means was significant $(t=2.83, \mathrm{df}=158$, $\mathrm{p}<.01)$. Individual one-tailed comparisons yielded significant differences between kindergartners and 2nd $(p<.05), 3$ rd $(p<.025)$, 5th $(p<.01), 6$ th $(p<.05)$, and 7 th $(p<.025)$ graders. Grades $1-7$ did not differ among themselves (see Fig. 1).

The results appear to be in line with the expectations of sensory-tonic theory and with its developmental application. The question of the relationship between magnitude of displacement and degree of convergence remains open. Correlation between interpupillary distance and displacement was positive, $(r=.07)$ but not significant, although interpupillary distance was significantly correlated with CA $(r=.64)$. Possibly, individual factors involving the force of convergence, for which we had no measure, overrode the slight increase with age which would occur due to increasing interpupillary distance.

Interestingly, assimilation displacements of targets following fixation change of counteractive displacements occur at about the same time that Wohlwill and others (Wohlwill, 1963) report a shift from under- to overconstancy for shorter distances. That phenomenon may be due to a relatively low-level response to stimuli produced by convergence unrelated to intellectual skills, but the failure to find a continuing trend beyond age seven renders such a conclusion extremely tenuous at this time.

\section{References}

Alpem, M. Types of movement. In H. Davson (Ed.), The eye. Vol. III, Muscular mechanisms. New York: Academic Press, 1962a. Pp. 63-143.

Alpern, M. Strabismus. In H. Davson (Ed.), The eye. Vol. III, Muscular mechanisms. New York: Academic Press, 1962b. Pp. 177-187.

Pollack, R. H. Application of the sensoritonic theory of perception to figural after-effect. Acta Psychologica, 1963a, 21, 1-16.

Pollack, R. H. Contour detectability thresholds as a function of chronological age. Percept. mot. Skills, 1963b, 17, 411-417.

Pollack, R. H. Backward figural masking as a function of chronological age and intelligence. Psychon. Sci., 1965, 3, 65-66.

Wapner, S., \& Wemer, H. Perceptual development. Worcester, Mass.: Clark University Press, 1957.

Wohlwill, J. F. The development of "over constancy" in space perception. In L. P. Lipsitt \& L. L. Spiker(Eds.), Advances in child development and behavior. New York: Academic Press, 1963. Pp. 265-312.

\section{Notes}

1. This research was supported by Grant No. HD 01433 awarded by the National Institute of Child Health and Human Development. 2. We are grateful for the cooperation of Mr. Darrell Holsteen, Superintendent of School District 89, Glen Ellyn, Illinois and his staff, Mr. Phillip Garret, Principal of Arbor View School and Mr. Robert Whitaker, Principal of Glen Crest Junior High School. 